\title{
Emerging sectors in rural development
}

\author{
Viaene, Jacques - De Steur, Hans \\ Department of Agricultural Economics, Faculty of \\ Bioscience Engineering, Ghent University, Gent \\ jacques.viaene@ugent.be
}

SUMMARY

This paper focuses on the innovativeness of rural economy and in particular on the way rural entrepreneurs in endogenous and exogenous sectors make use of their rural environment. building upon the sustainable innovation framework, key strategies for rural development are formulated. the described data refers to the rural innova region (10 rural eu regions). The results show that rural innovation is essentially a process of valorising endogenous potentials by connecting them with exogenous assets.

Keywords: rural development, sustainable innovation framework, strategies, European regions, endogenous, exogenous

\section{INTRODUCTION}

During the last decades agricultural sector in Europe is in transition, affecting agricultural sector and rural economy as a whole. The modernization model, characterised by intensification, scale-enlargement, specialization and integration into agribusiness chains is increasingly being abandoned in an effort to reduce the negative outcomes associated with the modernization model (Van der Ploeg, 1999). It led farmers to diversify their income by exploring alternative activities, of which some are new approaches to traditional agricultural farming while others are shifting away from the conventional focus on agricultural production.

These innovative strategies within the agricultural sector soon became a topic of interest for theorists who described them as new models for a sustainable rural development, e.g. multifunctionality (Van Huylenbroeck and Durand, 2003; Rizov, 2005), diversification (Hjalager, 1996) and broadening and deepening (Van der Ploeg et al., 2002).

This also resulted in policy models for integrated rural development and will persist during the next programming period of rural development policy (2007-2013) focussing on three key areas: the agrifood economy, the environment and the broader rural economy and population (EC, 2005).

As argued before, theorists and policy makers have developed strategies for the diversification of rural economy. However, while their position is clear, some questions rise with respect to the success of the rural entrepreneur to apply these strategies.

First, the question rises to which extent new strategies actually provide an alternative income for rural entrepreneurs. Earlier research indicates that until now this is rather limited.

Second, despite of continuous and partly successful efforts by the EU, the degree of innovation and entrepreneurship differs between regions (Guisán and Cancelo, 1998; Leonardi, 2006).

Third, studies reveal that the translation of rural development perspectives from the policy level to practice is difficult and depends upon the particular conditions that exist in given rural areas (Murdoch, 2000), whereby in particular differences between the perspectives of the actors involved in terms of orientations and aspirations should be taken into account (Leeuwis, 2000).

Therefore, this research will focus on the perception of the rural entrepreneur of the rural environment and -economy. Thereby the perceptions are compared between entrepreneurs in different sectors. This insight leads to recommendations for rural development to reinforce rural innovation and performance by aiming at important rural assets as they are perceived by the entrepreneurs. This paper focuses on innovative economic activities in rural regions. The primary aim is to develop strategies for non-farm rural development, whereby the differences are explored between two broad categories of non-agricultural economic activities: endogenous sectors, having a strong link with essential rural characteristics, through the utilization of rural natural resources (such as agriculture, nature and environment) and on exogenous sectors: demonstrating a weak or no link to rural characteristics but benefiting from advantages as result of their location.

The results are mainly based on data from the Rural Innova project, an EU-funded INTERREG IIIC project, aiming at stimulating interregional co-operation between 15 participating rural regions in the EU (see table 1).

Table 1

Participating regions in Rural Innova

\begin{tabular}{llll}
\hline \multicolumn{1}{c}{ Region } & Country & \multicolumn{1}{c}{ Region } & \multicolumn{1}{c}{ Country } \\
\hline East-Flanders & Belgium & Sousa & Portugal \\
Limousin & France & Andalucía & Spain \\
Corse & France & Extremadura & Spain \\
North Great Plain & Hungary & Wales & United Kingdom \\
Kaunas & Lithuania & Devon & United Kingdom \\
\hline
\end{tabular}

\section{INNOVATIONAND RURAL ENTREPRENEURSHIP}

This research focuses on the innovativeness of rural economy and in particular on the way rural entrepreneurs in endogenous and exogenous sectors make use of their rural environment. In this section these key elements are clarified.

\section{Sustainable innovation in rural areas}

A research framework is developed to study the strategies the rural entrepreneur applies to achieve its goals, in interaction with the various environmental factors, and its effect on innovation and sustainability. 
The sustainable innovation framework (SIF) is based on a society approach, which enables to study innovative activities from the point of view of a particular social group, in casu the entrepreneur. Thereby the topic is studied in terms of strategies that are applied by the subject to meet its goals. The model puts the entrepreneur in the centre of development. It enables to analyse activities in terms of multiple actors, sectors, strategies, outcomes and influences, taking into account dynamic change.

Central in the scheme are the rural capital assets, which influence the innovative behaviour of the entrepreneur. These assets are transformed by structures and processes, understood as the set of institutions, organisations, policies and legislation that shape rural economy, by determining the access to capital assets and decisionmaking bodies and by defining the terms of exchange.

By making use of capital assets and interacting with structures and processes the rural activity leads to positive or negative results in terms of innovation and performance. The outcomes, for their part, increase or decrease the sustainability of the system, and in that way influence the different components. The framework should not be read in a linear sequence, but as a set of mutually influencing factors.

Below the figure, rural development strategies are depicted. These strategies enhance the innovation, performance and sustainability of the system by influencing the capital assets and the structure- and process assets the entrepreneur makes use of (see figure 1).

Figure 1: Sustainable Innovation Framework (SIF)

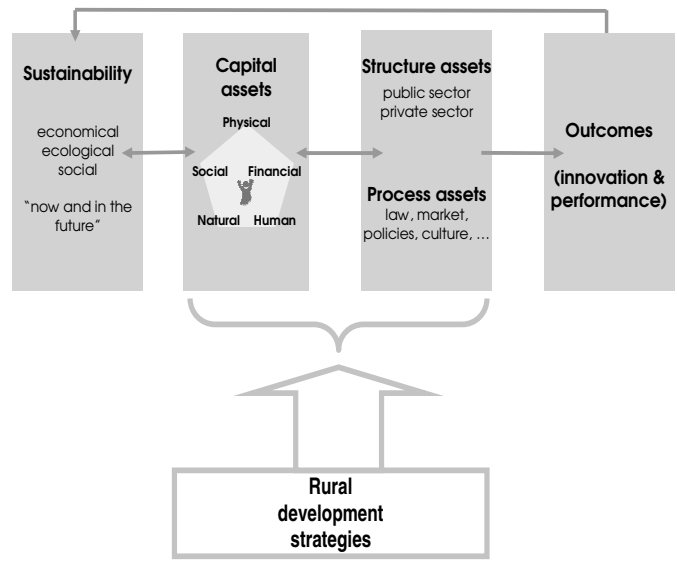

Source: adapted from DFID, 1999

Endogenous vs. exogenous sectors in rural economy

This research distinguishes two different economic sectors, depending of whether they result from endogenous or exogenous development.

- In the endogenous economic development local actors take responsibility for design and execution of development strategies. Endogenous development is based on local impulses, local actors, and grounded on local resources.

- In the exogenous model, economical development is driven by incentives or infrastructure which encourage external firms to locate in the rural area. The objective is to improve the production capacity of the region, in the hope that strong market linkages would be consolidated (Murdoch, 2000).

However, the difference between endogenous and exogenous development is not absolute. Contemporary rural development can be characterised as a "multilevel, multi-actor and multi-facetted process" (Van der Ploeg et al., 2000). In this multifunctional approach, a farm can perform a wide range of activities, of which some are extensions of the traditional agricultural farming (e.g. organic farming, short supply chains, regional products, ...) while others are shifting away (e.g. agri-tourism, care-activities, energy-production, off-farm activities) from the conventional focus on agricultural production. In this new range of activities, the gap between endogenous and exogenous can not be drawn sharply, as they valorise endogenous qualities, by addressing new exogenous demands.

The interrelations between exogenous and endogenous are understood as a continuum, demonstrated in Figure 2.

Figure 2: Rural activities in the endogenous-exogenous continuum

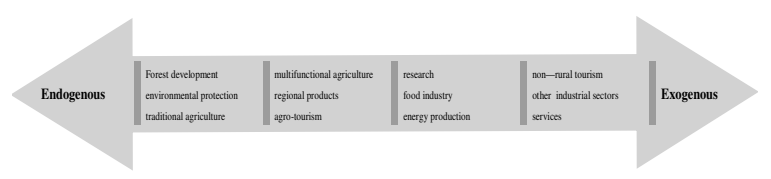

Activities that rely basically on natural resources are classified as strongly endogenous: forest development, traditional agriculture and environmental protection.

The second group encompasses multifunctional agriculture, regional products and agro-tourism. These are activities with strong linkages to agricultural and natural resources, but seek for a stronger connection to the external consumer.

In the third group, functional linkages are still present, but become weaker: research, food processing and energy production (non-agricultural). The fourth group encompasses activities where no functional link with agriculture is present, but where activities benefit from a rural location: certain industrial sectors and services, and tourism that is located in a rural environment without exploring rural qualities (e.g. attraction parks).

For research this implies that, first, a division between endogenous and exogenous is strictly conventional and, second, that the existing interrelationships must be stressed.

\section{OUTCOMES}

As explained in previous section, three main outcomes of rural economic activities are distinguished: innovation, performance and sustainability. The perception of each of these outcomes among endogenous and exogenous entrepreneurs is described in this section.

\section{Innovation}

Innovation is understood as an ongoing process of learning, searching and exploring, resulting in new products, new techniques, new forms of organisation and new markets (De Noronha Vaz et al., 2004; Lundvall, 1995). 
Except the forestry sector, all endogenous subsectors are perceived to be innovative to some extent. For rural tourism and agro-food sector organizational- and market innovation are perceived to be most important. Organizational innovation involves new ways to combine food processing and tourism with traditional farming and other activities. Marketing innovation refers to new ways to valorise traditional characteristics (regional products and methods, landscapes and cultural heritage). However, the focus groups indicate that only a small group of farmers implements these innovations, while the large majority of farmers continue to produce along the traditional agricultural production model.

Innovation in renewable energy and environmental protection is different: these subsectors are perceived as highly innovative. However the focus is here on productand process innovation, explained by the relatively recent introduction of these technologies.

The forestry sector is considered not innovative. This is because of the traditional character whereby forestry only provides an additional income (in the Mediterranean focus groups) or because of the industrial 'cut-and-sell' model (Kaunas). Nevertheless, important innovative approaches are developed in fire prevention.

The perception of the innovativeness of exogenous subsectors learns that none of the presented subsectors is considered strongly innovative. Rather than innovative sectors, the respondents perceive innovative firms and innovative developments. In the case of the food industry, the respondents indicate innovative market trends on the one hand and traditional production on the other hand. In non-food industry and public services different categories are distinguished, whereby highly specialised and technological industries and services are contrasted with lagging industrial sectors (textile, wood processing, porcelain) and basic services (construction, social services, transport).

Public services and non-rural tourism are perceived non-innovative. Public services are perceived passive, bureaucratic and hierarchical, which hampers the proactiveness and flexibility which is required for innovation. For non-rural tourism, no innovative uses of the rural environment is used, although there is potential.

\section{Performance}

Innovation is intimately linked with business performance (Aragon-Sanchez and Sanchez-Marin, 2005; Srivastava et al., 2005). In this respect, Kaplan and Norton (1992) distinguish innovation and learning as one of their four measures of performance. The other three perspectives are the financial-, customer- and internal business perspective. Therefore, in this research the innovation perspective is integrated with the other perspectives in achieving business performance in general.

Among the endogenous subsectors, the performance of agro-food sector and rural tourism sector is mainly explained by its value-added margin, and by its success in providing income and employment to the rural household. A factor hampering performance of these subsectors are the high investments required, involving risk.

Renewable energy production and environmental technology development are not considered performant within the rural environment. Despite the perception that these activities have a large potential, no value added derived for local society as only large-scale energy producers can bring up the required investments. However, the cooperative production model (whereby the consumer is shareholder in the power plant) is suggested as a way for rural economy to keep the value added in the region. Further, the situation is different for the production of energy crops, which is in line with traditional agricultural practice and is strongly embedded in rural economy.

The forestry sector, finally, is considered not performant due to the small-scale character and competitive disadvantages because of the import of exotic wood varieties.

Among the exogenous subsectors, the food and non-food industry and private services are considered performant sectors. In the non-food industry, the firms that are lacking the innovative capacity are also not performant. These sectors are considered not competitive on the globalised market. For private services, on the other hand, also the non-innovative services are performant, as they have a supportive function for the local society and economy. Together with the tertiarisation of economy, this creates a stable context for service development.

An important element for the focus groups to estimate the performance is the employment it generates. This is positively evaluated for the food industry and the private and public services sector. It is suggested that the role of public services as employer is even more important in economically less prosperous communities. However, the lack of efficiency and effectiveness is perceived as a threshold for performance.

\section{Sustainability}

Sustainability is considered as the outcome of the strategies on the firm within the broader environment, whereby the focus is on whether the strategies and outcomes of the firm are reconcilable with the ecological, economical and social aspects of the environment (DFID, 1999; Reheul et al., 2001). Except for the forestry sector, generally all endogenous sectors are sustainable. A fundamental change towards sustainability in agriculture resulted in the rise of agro-food activities and rural tourism. In the renewable energy subsector and environmental protection subsector ecological sustainability is achieved, rather than economical sustainability. Forest exploitation is considered unsustainable, both economical (severe global competition, low value added) and ecological (fire risk, immigrant wood varieties, awareness about ecology and fire risk is increasing, however not sufficient).

The exogenous focus groups associate the sustainability of exogenous sectors primarily with the environmental impact and economical stability. Social sustainability was not mentioned.

- On environmental sustainability, food industry and private services sector received a positive evaluation. For non-food industry, the situation differs between the regions: in some of the regions industrial firms control their environmental impact while in others this is not the case yet. This depends both of the mentality of the entrepreneurs and of the legal framework regulating their behaviour. Non-rural tourism is perceived unsustainable on this criterion 
primarily. Although a potential synergy with natural resources and rural tourism is perceived, this is not realised yet.

- Economical sustainability is perceived as the income stability of the subsector, which is positively evaluated in the food industry (explained by its basic and fresh character) and the private services (which have a supportive function for rural economy). Public services are perceived not stable, due to effect of specific problems like depopulation and lagging economy on the public financial means. Further, respondents perceive a lacking capacity to alter these dynamics.

\section{ASSETS OF RURAL ENTREPRENEURSHIP}

The analysis provides an extensive description of rural assets in the Rural Innova regions. This paper describes the important assets for the total sample. For an analysis of the regional differences and a more profound analysis reference is made to two studies (Gellynck et al., 2006; Vermeire et al., 2006).

The table below depicts the main perceived differences between endogenous and exogenous sector. Afterwards, the most important findings are described more in detail (see table 2).

Observing the table, the main differences between endogenous and exogenous sectors lie in the natural and physical capital assets. For natural assets, this is not surprising as the link with natural assets was one of the main criteria to classify the endogenous and exogenous sectors. However, it is remarkable that natural assets are perceived of no importance for exogenous sectors at all.

Concerning the physical capital assets, the comparison stresses the need for a multifunctional approach towards infrastructure in rural areas: on the one hand, both endogenous and exogenous sectors need fast connections with other

Comparison of assets between endogenous and exogenous sectors

\begin{tabular}{|c|c|c|}
\hline SIF & Endogenous sector & Exogenous sector \\
\hline 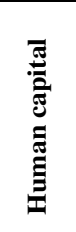 & $\begin{array}{l}\text { - Need for marketing \& management knowledge. } \\
\text { - On the one hand there are small-scale, family-based } \\
\text { entrepreneurs (primarily in agro-food sector, rural tourism and } \\
\text { forestry), on the other hand large-scale external investors } \\
\text { (renewable energy and environmental technology). } \\
\text { - Brain drain leading to depopulation and ageing communities. }\end{array}$ & $\begin{array}{l}\text { - Need for marketing- \& management knowledge in SME's. } \\
\text { - Brain drain leads to shortage in highly educated and technical } \\
\text { staff. However, education is also the main motivation for young } \\
\text { people to emigrate. }\end{array}$ \\
\hline 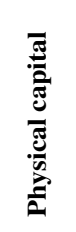 & $\begin{array}{l}\text { - 'Rural' mobility required: combining efficiency (fast } \\
\text { connections, qualitative infrastructure) with rural authenticity and } \\
\text { small-scale mobility. }\end{array}$ & $\begin{array}{l}\text { - Quick access on micro- and meso-level required: fast } \\
\text { connections with other regions and good accessibility of firms. } \\
\text { - Provision of qualitative industrial lands insufficient in many } \\
\text { regions. } \\
\text { - Internet opens business opportunities as it makes geography less } \\
\text { important. }\end{array}$ \\
\hline 苛 & $\begin{array}{l}\text { - Nature as a consumer attraction: aesthetic quality and } \\
\text { biodiversity support economic development. } \\
\text { - Climate change increasingly threatening in Mediterranean } \\
\text { regions. }\end{array}$ & Perceived not important. \\
\hline$\frac{\pi}{\frac{\pi}{2}}$ & $\begin{array}{l}\text { - Rural social cohesion is a strong asset. } \\
\text { - Family base both positive \& negative consequences: high } \\
\text { involvement and tacit knowledge base on the one hand and lack of } \\
\text { external orientation and formal knowledge on the other hand. } \\
\text { - Ecological awareness differs between regions. The 'not-in-my- } \\
\text { backyard' syndrome hampers new developments. } \\
\text { - Formal networks important for marketing \& knowledge } \\
\text { exchange. }\end{array}$ & $\begin{array}{l}\text { - Rural social cohesion is considered a strong asset as informal } \\
\text { relations are a strong instrument for business development. } \\
\text { - Formal networks, however, are also considered important, in } \\
\text { particular chambers of commerce, employer's organisations. It is } \\
\text { indicated that the participation in networks decreases in times of } \\
\text { recession. } \\
\text { - Ecological awareness differs between regions. }\end{array}$ \\
\hline 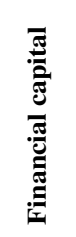 & $\begin{array}{l}\text { - Public incentives positively evaluated, however too much } \\
\text { bureaucracy. } \\
\text { - Lack of clear business plan in some firms decreases credit rating. } \\
\text { - The amount of investments required for the development of } \\
\text { renewable energy and environmental technologies is not feasible } \\
\text { for rural entrepreneurs. }\end{array}$ & $\begin{array}{l}\text { - Need for venture capital. } \\
\text { - In general, public funding is directed towards high-tech sectors } \\
\text { in particular, which makes them less significant for traditional } \\
\text { sectors. } \\
\text { - In isolated areas the financial means are lacking to support an } \\
\text { ambitious economic policy. }\end{array}$ \\
\hline 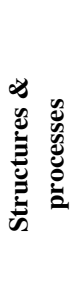 & $\begin{array}{l}\text { - Non-effective land use planning: new activities have new spatial } \\
\text { requirements. } \\
\text { - Innovative sectors address new geographical market } \& \text { market } \\
\text { niches. } \\
\text { - Burden of legislative and administrative obligations, which is a } \\
\text { threshold in particular for SME's. }\end{array}$ & $\begin{array}{l}\text { - Legislative obligations hamper flexibility which is important in } \\
\text { innovation processes. } \\
\text { - Quality assurance is a threat (investments) and an opportunity } \\
\text { (quality increase which could be valorised). } \\
\text { - Non-effective land use planning: lack of qualitative } \\
\text { infrastructure and transport efficiency. } \\
\text { - Globalisation opens markets for performant firms, but decreases } \\
\text { competitiveness for less-performant firms. }\end{array}$ \\
\hline
\end{tabular}


regions and good firm accessibility. On the other hand, the small-scale character and authenticity of rural mobility is an asset which is an element in the marketing of rural attractiveness.

The human and social capital assets, which are considered of major importance for all subsectors, are not radically different between endogenous and exogenous subsectors. Moreover, some possible synergies between the sectors appear: for some firms a lack of general marketing and management knowledge is perceived. The presence of exogenous firms can hereby lead to a broader orientation of endogenous entrepreneurs. Furthermore, exogenous focus groups state that the more intense informal relations and strong social networks in rural areas open opportunities as well.

\section{STRATEGIES FOR RURAL DEVELOPMENT}

The research indicates that the distinction between endogenous and exogenous sectors should be approached with caution. This is due to conceptual problems resulting from the exogenous-endogenous dichotomy. In contrary, it is argued that contemporary rural development aims at crossing the bridges between rural communities and the rest of society.

The analysis of the focus groups confirmed these theoretical statements by revealing a number of connections between endogenous and exogenous sectors:

- The production of wind energy makes use of intrinsic rural qualities (open space, mountains), however the amount of these investments is associated with large, exogenous energy providers.

- Rural regions with a good accessibility by highway can offer attractive locations for non-food industry due to less transportation costs.

- Rural tourism valorises endogenous qualities such as landscape, agricultural tradition, natural attractions. These endogenous qualities are valorised by attracting the foreign, external tourist.

- Industrial food production is increasingly internationally oriented and demand-driven. On the other hand the agricultural embeddedness is still perceived important, and endogenous qualities offer opportunities for regional product marketing.

These examples demonstrate that rural innovation involves aspects which can be labelled 'endogenous' and 'exogenous'. Therefore it is more feasible to focus on endogenous 'assets' of rural innovation than endogenous 'sectors'.

Moreover, the findings demonstrate that the development of innovation relies on both types of assets, whereby the new combination of endogenous and exogenous assets can be the source of innovation.

This leads to the conclusion that a strategic perspective on sustainable rural innovation should look for activities taking maximum benefit of endogenous and exogenous assets. This perspective is illustrated in the figure 3. below.

Endogenous assets refer to the rural assets the entrepreneur makes use of in achieving performance and developing innovations. The entrepreneur is located in the rural area and derives value added from his rural location because of the presence of these assets.

The degree of success of the strategy also depends of exogenous assets.
Figure 3: Endogenous and exogenous assets of sustainable rural innovation

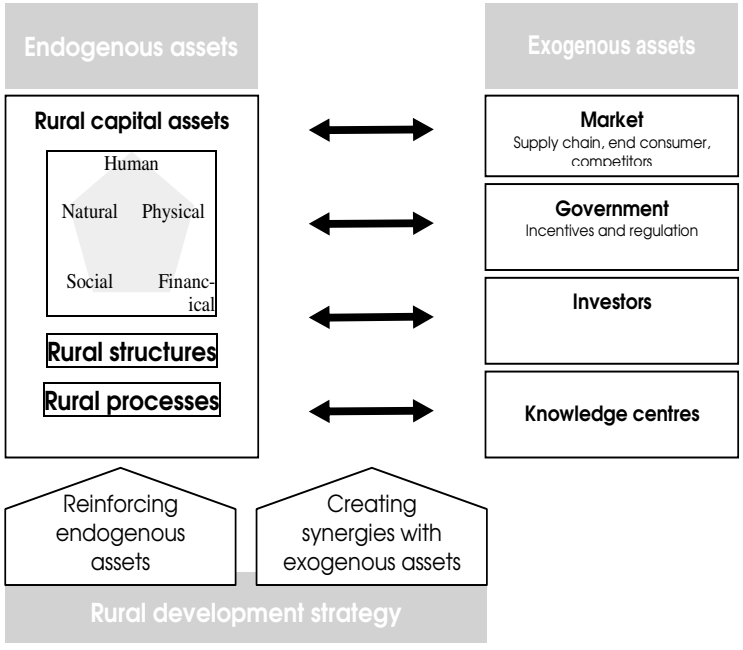

First, the exogenous market drives the development of innovation and performance growth. The market is hereby understood as the place where the firm meets the consumer, firms in the supply chain and competitors. Firms can be oriented towards the local consumer solely, however, in order to increase performance and develop innovations the firm will attract new consumers, on external geographical locations or in new market niches. Rural tourism, for example, relies on the value added that external customers give for exploring the rural region. On the home market and on the foreign market the entrepreneur deals with competitors and with the supply chain which consists of customers, suppliers and complementary activities. These relations are of particular importance in order to define what is new to the market and obtaining the necessary inputs from the chain (resources, knowledge) which may lead to innovations.

Second, government is an important institute for the development of rural economy. Government translates the wish of society (citizen) into regulations (e.g. quality assurance schemes, environmental legislation) and incentives (e.g. agro-environmental measures), which stimulate or restrict business development. Traditional agriculture, for example, is strongly directed by public support, but this is also the case for innovative activities (e.g. Leader+).

Third, the development of innovations requires investments. In the case of rural tourism and farmbased agro-food activities it is indicated that the own funds and rural investors are sufficient to start-up business. For more capital-intensive projects, such as renewable energy production, industrial activities or large-scale tourist infrastructure, this is perceived problematic. As such, the access to exogenous investors is necessary for rural entrepreneurs to start-up capital-intensive activities.

Fourth, similar to capital-intensity, different types of innovative activities are considered knowledge-intensive. This knowledge can be present in-house, however, in high-tech developments the access to external specialised knowledge is required. In different regions this external knowledge is not sufficiently available in the rural region, which forces entrepreneurs to search abroad for specialised knowledge. 
Taking into account the determinant impact of these exogenous assets, it is concluded that a strategic rural development perspective on innovation should focus at making new combinations of rural assets with exogenous assets offered by the market, government, investors and knowledge centres. This involves a twofold strategic aim for rural development:

- The first aim is to reinforce the endogenous assets where the entrepreneur can make use of to develop activities. The quality and nature of these assets determines economic development. For example, the cultivation of characteristic crops offers opportunities to market regional products, or the presence of good infrastructure leads the way for industrial development. However, the analysis demonstrates that this is not sufficient, as the success of rural economic activities depends upon exogenous drivers as well.

- Therefore, the second aim for rural development is to create synergies between endogenous and exogenous assets. Valorising the endogenous assets in the economic arena is heavily influenced by exogenous assets: by positioning his business within the supply chain, by applying for incentives and attracting investments, by developing markets and meeting with regulations.

In the following sections, these aims are further developed into strategic recommendations, starting from the focus group findings.

\section{Reinforcing endogenous assets}

Reinforcing the rural identity as a precondition for rural marketing

The analysis described a number of activities for which the good image of the rural region is a critical factor. This is the case for tourism activities and for food production (regional products). A strong rural or regional marketing is perceived as an instrument to protect rural economy against the forces of globalisation.

This marketing involves the communication of the rural identity towards the consumers/tourists. Obviously, the rural society and entrepreneurs have to experience this identity before they can communicate it. The findings suggest that this is sometimes lacking. As such, it becomes clear that initiatives concerning the promotion of rural tourism and the protection and marketing of regional products will fail when this does not respond to the entrepreneur's own identity. The marketing of the rural region should include measures for entrepreneurs to experience and actively construct identification with the region.

\section{Developing infrastructure with a rural profile}

The analysis demonstrated that the need for road infrastructure, utilities and industrial parks differs between the subsectors. On the one hand, the accessibility of the region by highways and public transport is required for industrial sectors, private services and for tourists to visit the region. Further, qualitative industrial zones are a necessity to attract businesses. On the other hand, the findings indicate that connection speed is not the only criterion for qualitative rural infrastructure. The rural area is also characterised by 'rural' mobility which is described as 'small-scale' and 'slow' and is integrated with the geographical profile of the region. This mobility is perceived as an essential characteristic of the rural area which attracts rural tourists and contributes to the rural image of the region.

To give growth opportunities to these different types of activities - depending of the strategic objectives of the region - both types of mobility should be part of the region's perspective on rural development.

Valorising the rural knowledge base through formal networking

In the focus groups, a number of characteristics of rural entrepreneurship returned throughout the descriptions. Entrepreneurship is thereby characterised by a strong reliance on the family base, resulting in high involvement and the efficient reproduction of tacit knowledge and specific expertise. Further, the entrepreneur is strongly embedded within the rural community through strong social cohesion, whereby information exchange takes place along informal networks.

In general, this rural entrepreneurship is positively evaluated. However, there are a number of drawbacks too: the strong reliance on the family relations and the near environment inhibits the acquisition of external knowledge. This is partly related to an individual orientation of the entrepreneur. Indeed, theory on innovation demonstrates that the acquisition of external knowledge is crucial for innovation. The focus groups confirm that the lack of formal knowledge hampers the adoption of new trends and technologies.

While the in-house knowledge base is strong, the acquisition of external knowledge sometimes fails. A specific task for rural development lies in stimulating network linkages with partners beyond the own social group.

\section{Embedding the knowledge base}

Innovation relies on the acquisition of external knowledge. Further, extension and training are the main instrument to upgrade the stocks of knowledge that are present within rural economy. However, education plays the ambiguous role of being a driver for depopulation at the same time. Different regions indicate that the higher education of young people outside the rural community leads to the emigration of these people to the university cities or to places with better career opportunities.

Therefore a particular challenge lies in embedding this human capital in the rural community. Three solutions follow from the analysis: creating job opportunities by stimulating rural economy, creating a business climate which stimulates these graduates to start their own business and offering qualities of living convincing people to stay or to move to the rural region.

\section{Creating synergies with exogenous assets}

\section{Marketing the region as a 'package'}

The success of regional food production and tourism depends strongly upon typical characteristics of the region - as they are perceived by the consumer: examples are the gastronomic tradition, natural landscape or a tradition of thermal bathing. Consumers thereby feel more attracted to a region where a variety of attractions is offered. The market potential of tourism and regional food products is dependent upon the total package of activities and images of the region. 
A challenge for rural development lies in, first, developing a total package of linked assets and activities and, second, communicating this total package to a broad audience of exogenous consumers.

As such, the focus groups suggest the common organisation and marketing between rural tourism and non-rural tourism, and the contribution of regional products and gastronomy. For rural development, consequently, the support to large-scale attractions may have a multiplier effect on rural tourism. However, possible negative effect must be taken into consideration, such as cannibalism between activities and environmental effects.

Reinforcing the orientation on the exogenous supply chain and competitors

Increasing the performance and innovation involves the acquisition of new knowledge and the development of new markets. This requires an insight in the international market, in order to define new opportunities and new ways to increase international competitiveness. Further, this requires insight in the international supply chain, in order to find the qualitative inputs for developing innovations.

As such, the challenge for rural development lies in orienting rural entrepreneurs towards the international competitive environment. Two ways can be followed: first, public initiatives can bring the international market to the region, by organizing activities such as fairs and seminars providing information about specific themes in an international perspective. Second, public initiatives can train entrepreneurs to extend there orientation to the international scale. This second option is presumably more efficient, as it offers the entrepreneur the skills to find leading-edge knowledge, depending of his personal business perspective.

\section{Consulting rural entrepreneurs about regulations and incentives}

The role of the government is twofold: on the one hand, regulations define the framework where entrepreneurs can take initiative, on the other hand incentives are provided to support specific, desired developments. The focus groups indicated that entrepreneurs have difficulties to find their way in the complex legislation, despite the fact that changes in legislation also offer opportunities for development (e.g. quality assurance, environmental legislation). The same holds true for incentives: although there are considerable incentives for innovation, rural- and regional development at different policy levels, some entrepreneurs do not make use due to a lack of knowledge about these incentives and the skills to obtain them.

Rural development should enhance the capacity of entrepreneurs to develop activities meeting with regulations and taking maximum benefit from the incentives which are available. To do this, different pathways are advised: first, public consultancy should be provided to entrepreneurs, where advise is offered starting from the business ideas of the entrepreneur. Second, education and training of farmers and rural entrepreneurs should provide the right skills to understand and deal with regulation and to find and negotiate incentives.

\section{Supporting capital creation}

The analysis demonstrates that the rural environment offers a number of assets which bring high-tech innovative developments into perspective. Examples are the presence of natural assets for the production of renewable energy and the development of environmental technology.

At present, the impact of these subsectors on rural economy is limited, due to the high capital-intensity to develop these activities. As a result these developments take place in stronger economic complexes or take place within rural areas but initiated by exogenous investors exporting the value added outside the region.

Enhancing the capacity of entrepreneurs to attract investments implies that these activities become an option for rural entrepreneurs. Two options are possible:

- Supporting the development of business models which permit to gather a sufficient amount of endogenous capital. An example of this option is the cooperative business model to start-up wind energy production.

- Enhancing the negotiation skills of rural entrepreneurs to convince exogenous investors. The chances for success increase when entrepreneurs can demonstrate a good business plan with well-founded strategic objectives. Public initiatives can aim at training entrepreneurs, or intervene in the negotiation process by assisting the entrepreneurs.

\section{CONCLUSIONS}

The research results presented in this paper encompass an exploration of the relation between entrepreneurship and the rural environment in 10 rural EU regions. The results reveal a number of dynamics which should be taken into account in rural development planning and can be further developed in future research.

The analysis of the entrepreneurial perception of the rural environment demonstrates that rural innovation is essentially a process of valorising endogenous potentials by connecting them with exogenous assets.

This implies that rural development should aim to reinforce these endogenous potentials on the one hand, and stimulate endogenous actors to recognise exogenous assets and take benefit of them. While stimulating endogenous growth is an important objective in contemporary rural development, less attention is paid to the way in which entrepreneurs aim their business strategy at exogenous assets. In these cases rural development should broaden their scope and connect rural economy with exogenous markets, investors, knowledge centres and public actors.

\section{REFERENCES}

Aragon-Sanchez, A.-Sanchez-Marin, G. (2005): Strategic orientation, management characteristics, and performance: A study of Spanish SMEs. Journal of Small Business Management. 43. 3: 287-308.
De Noronha Vaz, T.-Viaene, J.-Wigier, M. (2004): Innovation in small firms and dynamics of local development. Scholar Publishing House. Warsaw. 
DFID (1999): Sustainable livelihoods guidance sheets. London, DFID.

EC (2005): Council decision on Community strategic guidelines for Rural Development (Programming period 2007-2013): Council of the European Union.

Gellynck, X.-Vermeire, B.-De Steur, H.-Viaene, J. (2006): Comparative study of emerging sectors in rural development. Exogenous sector: food \& non-food industry, private \& public services and nonrural tourism. Ghent University. Ghent.

Guisán, C.-Cancelo, T. (1998): Evaluation of the effects of European regional policy in the diminution of regional disparities.

Hjalager, A. M. (1996): Agricultural diversification into tourism Evidence of a European Community development programme. Tourism Management. 17. 2: 103-111.

Huylenbroeck, G. V.-Durand, G. (2003): Multifunctional agriculture. A new paradigm for European agriculture and rural development Ashgate. Hampshire.

Kaplan, R. S.-Norton, D. P. (1992): The balanced scorecard: Measures that drive performance. Harvard Business Review. 83. 7: 172.

Leeuwis, C. (2000): Reconceptualizing participation for sustainable rural development: Towards a negotiation approach. Development and Change. 31. 5: 931-959.

Leonardi, R. (2006): Cohesion in the European Union. Regional Studies. 40. 2: 155-166.

Lundvall, B. (1995)- National systems of innovation: towards a theory of innovation and interactive learning. Biddles Ltd. London.
Murdoch, J. (2000): Networks - a new paradigm of rural development? Journal of Rural Studies. 16. 4: 404-419.

Reheul, D.-Marthijs, E.-Relaes, J. (2001): Elementen voor een toekomstvisie mbt. een duurzame land- en tuinbouw in Vlaanderen. [In: D. A. Ministry of the Flemish Community (ed.)]

Rizov, M. (2005): Rural development under the European CAP: The role of diversity. The Social Science Journal. 42. 4: 621-628.

Srivastava, P. K.-Kulshreshtha, K.-Mohanty, C. S.-Pushpangadan, P.Singh, A. (2005): Stakeholder-based SWOT analysis for successful municipal solid waste management in Lucknow, India. Waste Management. 25. 5: 531-537.

Van der Ploeg, J. (1999): Endogenous development: practices and perspectives in Europe (pp. Compas Newsletter). LEI. Wageningen.

Van der Ploeg, J.-Long, A.-Banks, J. (2002): Rural development: the state of the art. [In: Van der Ploeg, J.-Long, A.-Banks, J. (eds.) Living countrysides.] Rural development processes in Europe: the state of the art. Doetinchem: Elsevier bedrijfsinformatie bv.

Van der Ploeg, J.-Renting, H.-Brunori, G.-Knickel, K.-Mannion, J.-Marsden, T.-de Roest, K.-Sevilla-Guzman, E.-Ventura, F. (2000): Rural development: From practices and policies towards theory. Sociologia Ruralis. 40. 4: 391.

Vermeire, B.-De Steur, H.-Viaene, J. (2006): Comparative study of emerging sectors in rural development. Endogenous sectors: Agro-food, rural tourism, forestry resources, renewable energy \& environmental protection. Ghent University. Ghent. 